\title{
Costs of group-living for a normally solitary forager: effects of provisioning tourism on southern stingrays Dasyatis americana
}

\author{
Christina A. D. Semeniuk ${ }^{1, *}$, Kristina D. Rothley ${ }^{1,2}$ \\ ${ }^{1}$ School of Resource and Environmental Management, Simon Fraser University, 8888 University Dr., Burnaby, \\ British Columbia V5A 1S6, Canada \\ ${ }^{2}$ Present address: Department of Biology, Kutztown University of Pennsylvania, 15200 Kutztown Rd., Kutztown, \\ Pennsylvania 19530-0730, USA
}

\begin{abstract}
Animals can perceive tourists as predators and will incur fitness costs should their predator-avoidance behaviours result in forgone resource acquisition. Not all wildlife, however, treat tourists as predators; animals can respond positively to tourists, especially when food is used as an attractant. We investigate the costs posed by novel grouping over a tourism-provisioned food resource in a normally solitary forager, the southern stingray Dasyatis americana, in Grand Cayman. Specifically, we test the hypotheses that group-living stingrays in a new environment-which includes both the presence of tourists and quickly renewing food patches - will be exposed to increased injuries, ecto-dermal parasites and aggressive interference competition that result from the unusual grouping behaviour. We found that, in comparison to stingrays from non-tourist sites, touristfed stingrays are more likely to have lower body condition, be injured by boats and predators, be susceptible to ecto-dermal parasites, and be engaged in intense interference competition (in the form of conspecific bite marks). Stingrays from tourist sites also have significantly higher mean numbers of injuries, parasites, and median bite marks. By exploring alternative hypotheses to explain the pattern of our findings (e.g. natural causes/behaviour), we unequivocally show that the impacts incurred by the stingrays stem from the effects of tourism. These findings suggest that novel grouping poses costs to the stingrays; the tourist site represents a riskier habitat with regards to injury and predation; and there may be long-term fitness consequences. From a management perspective, measures should be taken to alleviate the crowded conditions at tourist sites, in terms of both boat and stingray density.
\end{abstract}

KEY WORDS: Grouping costs · Predation risk · Injury · Parasites · Aggression · Stingray · Tourism

Resale or republication not permitted without written consent of the publisher

\section{INTRODUCTION}

Understanding how animals perceive humans is an important aspect of conservation and wildlife biology, as it allows managers to predict animal responses to human disturbances, determine whether these actions are adaptive, and to effectively mitigate human-wildlife conflicts. A burgeoning concern in wildlife management is the direct interaction between humans and wildlife in the form of wildlife tourism (Duffus \& Dearden 1990, Reynolds \& Braithwaite 2001). Wildlife tourism is an example of a rapidly growing industry seen as a catalyst for economic and social development, and a way for wildlife to 'pay for itself' (Rubenstein 1998, Milazzo et al. 2006). However, wildlife tourism can be prone to unmitigated development to promote visitor satisfaction that is bought at the cost of ecological integrity (Newsome et al. 2005). Attempting to control the impacts of wildlife tourism on a focal species requires research into how different species respond to different types and levels of human disturbance, so that management can be implemented accordingly.

One form of response evoked by human-caused disturbance stimuli is a predator-avoidance strategy in 
animals. Such behaviour creates tradeoffs between avoiding perceived predation risks and other fitnessenhancing activities (Lima \& Dill 1990, Gill \& Sutherland 2000). For instance, many animals respond to human disturbance as they do to their natural predators by increasing vigilance, increasing group size, abandoning the site, selecting alternative habitats, altering mate choice, and/or adjusting life-history decisions (Frid \& Dill 2002, Beale \& Monaghan 2004, Blumstein 2006). These behavioural outcomes thus pose a cost to the animal in terms of fitness maximization in reproductive success and/or survival. Wildlife tourists represent an example of a disturbance stimulus, and, indeed, a multitude of studies have demonstrated that, in the presence of tourists, animals exhibit increased predator-avoidance energy expenditure, augmented circulating stress hormones, compromised immune function, reduced body condition, and decreased reproduction and survival of animals (Knight \& Cole 1995, Ikuta \& Blumstein 2003, Lusseau 2003, Müllner et al. 2004, Amo et al. 2006). While overwhelming, evidence of wildlife reacting to tourists as predators is not the sole response elicited. Tourists can also be perceived as refugia, either through reducing the risk of predation from conspecifics (i.e. vulnerable age/sex class; Nevin \& Gilbert 2005), or through providing resources such as food (Milazzo et al. 2006, Laroche et al. 2007), thereby increasing energy allocation to other fitness activities such as rest and reproduction (Orams 2002). Wildlife in these instances is attracted, not repelled, to tourists, since the immediate outcomes of this association can provide benefits. However, even when tourists are considered a positive stimulus, indirect costs can still result, especially if the life-history characteristics of the animal are altered by the wildlifetourism activity. In particular, grouping in a normally solitary animal due to the attraction to tourists is predicted to give rise to costs.

Animals typically form groups to enhance foraging efficiency, improve locomotory ability, increase mating encounters, benefit from alloparental care, maintain physiological parameters, or to lower individual risk of predation. Animals may also form groups incidentally, in response to limited, patchy resources such as mates, refuge habitat, and food. Although grouping can be an effective fitness strategy, not all individuals are found in groups, some groups are maintained at sizes well below their predicted optimum (Steenbeek \& van Schaik 2001), and some animals group only under certain conditions. Such evidence suggests there are costs associated with the formation of groups, including increased conspicuousness, increased competition for resources, increased levels of aggression, and increased exposure to parasites or disease agents (Krause \& Ruxton 2002). While these explanations can describe why animal populations can presently be found to live in groups or alone, i.e. already at their evolutionary equilibrium, they can equally explain what costs, if any, exist for animals newly transitioning from solitary to grouping behaviours.

In the present study, we investigate some potential costs of grouping in a typically solitary forager, the southern stingray Dasyatis americana, which congregates over a quickly renewing, patchy resource, namely, provisioned food (squid) supplied by marinewildlife tourists in the Caribbean. At Grand Cayman, 'Stingray City Sandbar' (SCS) is a tourist attraction approximately $7740 \mathrm{~m}^{2}$ in area and located in a shallow sound in the north of the island. Up to 2500 tourists from 40 tour boats can be simultaneously present at SCS feeding, touching, and holding stingrays as part of their marine tourism experience, which occurs yearround (Shackley 1998). Since the site's inception in 1984, an aggregation of over 100 tagged and identified stingrays of both sexes can now be found at SCS at a given time, feeding on squid provided by tourists. Previous research in the Grand Cayman system has established that the tourist stingrays have altered their behaviours in response to the provisioned food in terms of reduced activity space, strong and persistent site fidelity, and a shift to diurnal behaviours in comparison to stingrays from non-tourist sites at Grand Cayman (Corcoran 2006). Stingrays are also accustomed to the supply of artificial food; a comparison in serum fatty acid profiles between stingrays from tourist and nontourist sites show marked differences, suggesting squid to be the major food item in the diet (Semeniuk et al. 2007). Additionally, SCS now represents not only a foraging patch but also a mating site, as stingrays can be observed mating (Chapman et al. 2003), and are presumed to copulate year-round, since females in obvious states of gravidity (stingrays are live-bearers) can be readily observed throughout the year (M. Corcoran pers. comm.). As a result, SCS has now become a permanent habitat for a large population of rays. Despite the purported benefits of stingray group-living at SCS, such as reduced energy expenditure in searching, capturing and handling prey, and possibly increased reproductive effort, potential costs of grouping have not been examined in this normally solitary forager.

The grouping costs examined in the present study focus on the possible negative impacts incurred by grouping: (1) in a novel environment, i.e. in the presence of tourists, and (2) around a newly occurring food source. Specifically, we set out to test the hypotheses that, in comparison to solitary stingrays from nontourist sites, group-living stingrays at the tourist site would have increased incidence of injuries (from boats and predators), higher parasite loads (due to increased transmission rates), and a greater number of conspe- 
cific bite marks (CBMs, due to increased interference competition between individuals over the centralized food sources). While speculated, no study has systematically measured the suggested costs of altered behaviours of the targeted species from marine-provisioning tourism. We conclude with speculations as to whether the costs imposed by the tourism attraction can be of any consequence to the long-term physiological fitness of the stingray population, and discuss our findings in the light of wildlife management.

\section{MATERIALS AND METHODS}

Study species and study site. The southern stingray Dasyatis americana is a long-living (ca. 26 yr; Henningsen 2002), common inshore ray frequenting tropical and subtropical shallow bays of the southern Atlantic Ocean, Caribbean and the Gulf of Mexico. It is a continuous forager, feeding opportunistically on a varied diet of crustaceans and teleosts, and, to a lesser extent, on molluscs and annelids (Gilliam \& Sullivan 1993). Although southern stingrays inhabit all shallow bays around the Cayman Islands, it is only in the vicinity of SCS that these rays can be found year-round in a dense aggregation of individuals of both sexes. This amassment results from the unregulated quantity of provisioned squid (Illex and Loligo spp.), a non-natural diet item shipped in from the North Atlantic and North Pacific (C.A.D. Semeniuk pers. obs., Gina Ebanks-Petrie, Director, Cayman Islands Department of Environment pers. comm.). The feeding routine (daily, except during the summer months when weekends are excluded) lasts from early morning until mid-afternoon as tour boats continuously deliver tourists (mainly cruise line passengers) for an average $45 \mathrm{~min}$ visit to SCS. The food provided is abundant, but delivered at discrete focal points (multiple floating buckets supplied by each tour boat). In general, benthic stingrays forage solitarily; they congregate during the breeding season, and occasionally aggregate when resting or when space is limited (Tricas et al. 1997). As a result of the tourist-feeding regime, the stingrays from tourist sites have become diurnal (in contrast to their non-tourist counterparts around the island), and have reduced their activity space to the shallow waters immediately surrounding the feeding area (Corcoran 2006). A total of 172 individuals from the tourist site have been tagged since 2002 . The rays have a mean yearly recapture rate of $92.5 \%(0.03 \mathrm{SD}$; C. A. D. Semeniuk unpubl. data), and tracking studies over 2 yr show restricted movements to the tourist site (Corcoran 2006), indicating a very strong temporal and spatial fidelity to the feeding site.

Data collection. Immature and adult stingrays were captured at SCS and from 3 control, non-tourist sites on the southern (opposite) side of Grand Cayman. Stingrays from the non-tourist sites do not interact with the tourists at SCS (from acoustic-telemetry tracking data; Corcoran 2006). Stingrays from tourist sites are accustomed to human presence and easily captured by simply holding them against one's chest when they approach for food. Once caught, a ray was placed in a landing net (1 $\mathrm{m}$ diameter) and transferred into a seawater-filled canvas pool $\left(4 \mathrm{~m}^{2}\right)$ aboard a $7.32 \mathrm{~m}$ long, $225 \mathrm{hp}$ dusky boat. Control rays from non-tourist sites were located visually from a $4.27 \mathrm{~m}$ long, $45 \mathrm{hp}$ double hull boat, and then encircled in a hand-drawn seine net (9.14 m long), guided into a landing net, and transferred aboard into the holding pool. Once transferred, binder clips were placed over the barb on the ray's tail for protection, and, in an average of $15 \mathrm{~min}$, the ray was identified or tagged (with a passive integrated transponder, PIT), weighed, its disc width measured, injuries recorded, and dermal parasites counted in the spiracles (ventilatory organs located behind the eyes that pump oxygenated water over the gills). Upon completion of the examination, stingrays were placed back into the landing net, had the tail clip removed, and were gently returned to the water. When released, fed stingrays usually resumed feeding at once, while nonfed rays swam away from the immediate area.

Data used in the present study are from 2 sampling periods: May to July 2004, and October to November 2005. Because this study is part of a larger research program investigating the general, physiological and immunological impacts of stingray provisioning tourism, different indicators were analysed from different sampling occasions. Analyses of injuries and dermal parasites originate from the 2005 dataset as this represents the most complete dataset; CBMs are from the 2004 dataset, and body condition indices are presented for both years. Due to strong site fidelity, stingray longevity and consistent environmental conditions, we do not expect significant yearly differences within tourist and non-tourist groups. With the exception of CBM data, all other data are presented for females only, as just $18 \%$ of the 172 tagged rays at the tourist site are males. Moreover, as the tourist attraction is currently undergoing ecological (and social) management directives, we focused our research on females, as animals of this sex will be the major recipients of any management actions. Hence, for monitoring purposes, targeting females is the most efficient choice. Males are incorporated into the analysis of CBMs solely to test the alternative hypothesis that increased bite mark incidence and number are attributable to increased mating attempts, not interference competition.

Analysis. A size-distribution comparison between rays from tourist and non-tourist sites was made by fitting an analysis of covariance to log-transformed 
weight versus length data, with location (tourist site and non-tourist sites pooled) as a factor variable for 2004 and 2005. The size data were then pooled between the sites within each year, and residuals were calculated to estimate body condition. A non-parametric $t$-test (as our assumption of homogeneity of variances was violated) was next conducted to determine whether stingray body condition differed significantly between tourist and non-tourist sites for the 2 different years.

The effect of location on the probability of captured stingrays having a boat-, predator-, or conspecificinflicted injury, ectodermal parasites in their spiracles, or a CBM was analysed separately with general linear model (GLM) nominal logistic fit regression. Analyses were executed in JMP IN 6.0 (SAS Institute, Ver. 2005), treating presence and absence of wounds and parasites as a binary dependent variable, and location as a dummy independent variable. Also included in the model as continuous independent variables were disc width (cm, log transformed), to control for the effect of stingray size, and body-size metrics (taken as residuals of stingray length-weight regression for all sites combined), to control for stingray body condition.

To test for differences in the mean number of injuries and parasites when present (i.e. stingrays exhibiting no injuries or parasites were excluded) between tourist and non-tourist sites, these dependent variables were first transformed to satisfy the assumptions of normality and equality of variance, and then analysed in a least-squares multiple regression, using location as a dummy independent variable, and disc width (cm, log transformed) and bodysize metrics as continuous independent variables.

As stingrays at the tourist site are larger, on average, than those sampled from non-tourist sites (Table 1), we tested the alternative hypothesis using chi-squared contingency tests that injury frequency is a function of age (using size as a surrogate) and not a result of the impacts of tourism. Therefore, larger (i.e. older) animals should have proportionally more injuries than smaller animals, at both tourist and non-tourist sites. Injury type was also explored and compared between tourist and non-tourist sites, with injuries separated into 3 categories: injuries that affect predator-detection/defence (e.g. missing, damaged, or broken sections of the tail and barb), injuries that can cause infection (e.g. abrasions, fresh wounds, severe CBMs, boat-propeller cuts, abnormal growths), and injuries that can affect motility (e.g. excisions out of the pectoral fins, missing fins, old, calcified scars, reset skeletal-cartilage breaks). The proportions of these injury types were compared with chi-square tests between tourist and non-tourist locations.

CBM counts were compared between tourist and non-tourist groups controlled for size ( $\mathrm{cm}$, log disc width) and sex using a GLM with a log-link Poisson distribution. Effects of sex were then explored independently, to determine whether bite marks were indicative of increased mating effort or of interference competition. Specifically, CBM counts were compared between immature $(<47 \mathrm{~cm}$ disc width; Guy Harvey Research Institute unpubl. data) and mature males in both the tourist and non-tourist groups separately; differences in the number of CBMs were compared among females of 3 size categories: $\leq 65,66$ to 90 and $\geq 91 \mathrm{~cm}$ disc width, and between tourist and non-tourist sites, using the contrast option of the GLM procedure of the JMP software.

\section{RESULTS}

\section{Size distribution, body condition}

Female stingrays Dasyatis americana were larger, in terms of both disc width and weight, at the tourist site than females sampled from the non-tourist sites for both 2004 and 2005 (median $_{\text {tourist }}=99$ to $100 \mathrm{~cm}$ disc width,

Table 1. Dasyatis americana. Variable medians and means. * Significant difference between tourist and non-tourist sites. CBMs: conspecific bite marks

\begin{tabular}{|lcc|}
\hline Variables & Tourist site & $\begin{array}{c}\text { Non-tourist } \\
\text { sites (pooled) }\end{array}$ \\
\hline 2004 median disc width & 99,32 & $78,14.5$ \\
$(\mathrm{~cm})$, weight $(\mathrm{kg})^{*}$ & $(\mathrm{n}=74)$ & $(\mathrm{n}=53)$ \\
2005 median disc width & 100,33 & $76.5,15$ \\
$(\mathrm{~cm})$, weight $(\mathrm{kg})^{*}$ & $(\mathrm{n}=46)$ & $(\mathrm{n}=50)$ \\
2004 mean \pm SE body & $-0.84 \pm 0.55$ & $-0.02 \pm 0.65$ \\
condition (length-weight residuals) & $(\mathrm{n}=74)$ & $(\mathrm{n}=53)$ \\
2005 mean \pm SE body & $-1.11 \pm 0.79$ & $0.92 \pm 0.76$ \\
condition (length-weight residuals) ${ }^{*}$ & $(\mathrm{n}=46)$ & $(\mathrm{n}=50)$ \\
Least-squared mean number of & $3.6 \pm 0.10$ & $1.9 \pm 0.17$ \\
injuries (back-transformed) \pm SE $^{*}$ & $(\mathrm{n}=39)$ & $(\mathrm{n}=15)$ \\
Least-squared mean number of spiracle & $9.1 \pm 1.7$ & $6.7 \pm 1.7$ \\
parasites (back-transformed) \pm SE $^{*}$ & $(\mathrm{n}=44)$ & $(\mathrm{n}=42)$ \\
Median number of CBMs & & \\
Immature male & $7(\mathrm{n}=3)$ & $0(\mathrm{n}=19)$ \\
Mature male & $14(\mathrm{n}=11)$ & $0(\mathrm{n}=4)$ \\
$\leq 65 \mathrm{~cm}$ disc width female & $6(\mathrm{n}=6)$ & $0(\mathrm{n}=6)$ \\
$66-90$ cm disc width female & $22(\mathrm{n}=15)$ & $5(\mathrm{n}=24)$ \\
$\geq 91$ cm disc width female & $21(\mathrm{n}=54)$ & $15(\mathrm{n}=8)$ \\
& & \\
\hline
\end{tabular}


32 to $33 \mathrm{~kg}$ median $_{\text {non-tourist }}=76.5$ to $78 \mathrm{~cm}$ disc width,

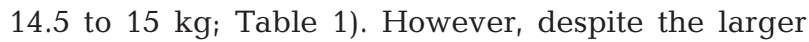
size, growth trajectories (i.e. log-transformed disc width and weight relationship) were not significantly different between the 2 locations (ANCOVA, 2004: $F_{2,127}=$ $\left.2.74, \mathrm{p}_{\text {location }}=0.28 ; 2005: F_{2,96}=1.92, \mathrm{p}_{\text {location }}=0.12\right)$, signifying that tourist-fed rays are not significantly heavier for a given size. Body condition, measured as residuals of the logarithmic relationship between disc width and weight for the tourist and non-tourist sites combined, did not differ significantly between sites in the 2004 season $\left(\bar{x}_{\text {non-tourist }}=-0.026 \pm 0.64 \mathrm{SE}, \bar{x}_{\text {tourist }}=\right.$ $-0.840 \pm 0.54 \mathrm{SE}$; Mann-Whitney $U$-test $=0.72, \mathrm{p}=0.47$, effect size $=0.17$; power $=0.16$ ). The effect was, however, in the opposite expected direction. In 2005, body condition, in this instance, was significantly lower at the tourist site $\left(\bar{x}_{\text {non-tourist }}=0.92 \pm 0.76 \mathrm{SE}, \bar{x}_{\text {tourist }}=-1.11 \pm\right.$ $0.79 \mathrm{SE}$; Mann-Whitney $U$-test $=-2.15, \mathrm{p}=0.03$ ), again in the opposite direction of what was expected.

The logistic models showed no significant effect of body condition on the incidence of wounding or CBMs, but did have an effect on the likelihood of being host to ectoparasites (non-tourist site only).

\section{Injury frequency, type}

The probability of a stingray being injured increased with increasing disc width, and was much higher for tourist stingrays than for non-tourist stingrays $\left(\chi^{2}\right.$ model $=$ $36.32, \mathrm{p}<0.001 ; \chi_{\text {disc width }}^{2}=4.78, \mathrm{p}=0.026, \beta=-2.23$; $\left.\chi_{\text {location }}^{2}=19.42, \mathrm{p}<0.001, \beta=1.11\right)$. Thirty percent $(\mathrm{n}=$ 50 ) of stingrays from the non-tourist sites were injured versus $85 \%(n=46)$ from tourist sites (Fig. 1). This pattern was not the result of stingrays at the tourist site being larger, on average, since, when categorized by size $(\leq 65,66$ to 100 and $\geq 101 \mathrm{~cm} \mathrm{dw})$, the proportion of stingrays injured at the tourist site was equally distributed across the 3 size categories $(60,85$ and $86 \%$, respectively; $\chi^{2}=3.00, \mathrm{p}=0.22$ ). At the nontourist sites, the proportion injured increased (as expected) with size $(17,30$ and $60 \%$, respectively; $\left.\chi^{2}=13.35, \mathrm{p}=0.001\right)$.

The average number of injuries per stingray (square-root transformed) was positively influenced by stingray size and by location, with stingrays from tourist sites having significantly more injuries $\left(\mathrm{R}_{\text {adj }}^{2}=0.28, t_{\text {disc width }}=2.21, \mathrm{p}=\right.$ $0.032, t_{\text {location }}=-3.26, \mathrm{p}=0.002$, effect size $=0.9$; least squares back-transformed means $\pm \mathrm{SE}: 3.6 \pm 0.1$ and $1.9 \pm$ 0.17 injuries per stingray from tourist and non-tourist sites, respectively; Table 1). With regards to injury type, predator detection/ defence injuries were common to stingrays from both tourist and non-tourist sites (Table 2), whereas one-half of the infection susceptibility and motility-impairment injuries were unique to those from tourist sites (Fig. 2). Only the fish-hook injury was unique to stingrays from non-tourist sites. With respect to the proportion of injury types, 33\% of the injuries at the tourist site were predatordetection/defence injuries, $47 \%$ were susceptible-toinfection wounds and $20 \%$ were motility-impairment injuries. These percentages are in significant contrast to the injuries recorded at the non-tourist sites, the distribution of which was as follows: $41 \%$ were predatordetection injuries, $18 \%$ were susceptible-to-infection wounds and $41 \%$ were motility-impairment injuries $\left(\chi^{2}\right.$ $=36.67, \mathrm{p}=0.001$ ).

In specific, the predominant injury to stingrays from non-tourist sites was a shortened tail, which we assume to be the result of a predator attack (Dahlberg 1970). As for predator scars or injuries at SCS, missing

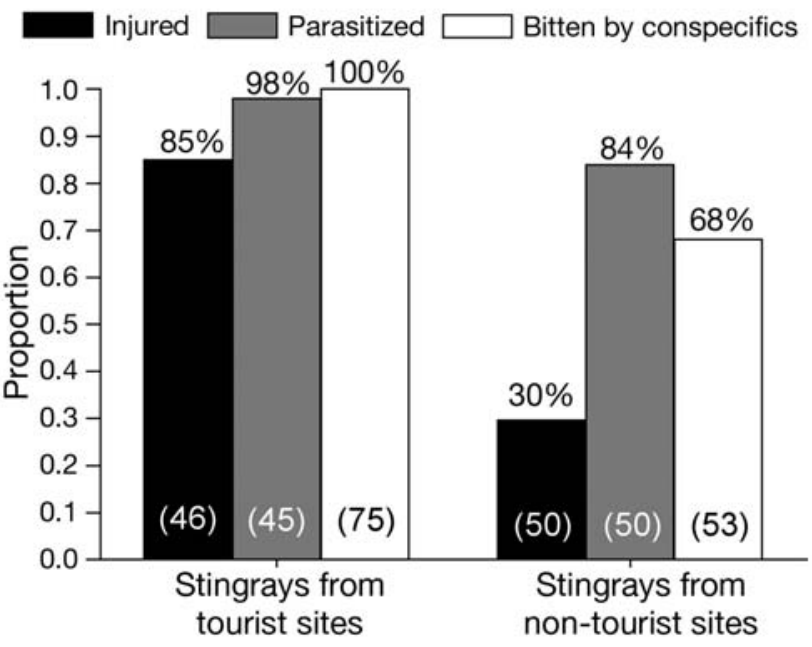

Fig. 1. Dasyatis americana. Proportion of female stingrays injured, parasitized and bitten by conspecifics in relation to tourist and non-tourist sites. Numbers in parentheses refer to sample sizes

Table 2. Dasyatis americana. List of injuries recorded and their category type

\begin{tabular}{|c|c|c|}
\hline $\begin{array}{l}\text { Predator- } \\
\text { detection/defence }\end{array}$ & Susceptible-to-infection & Motility-impairment \\
\hline Missing tail & Propeller cut ${ }^{\mathrm{a}}$ & Excisions in fin \\
\hline Missing barb & Fresh wound/abrasion & Large clefts in fin ${ }^{a}$ \\
\hline Damage to tail (broken) & Abnormal body growths ${ }^{\mathrm{a}}$ & Missing fin ${ }^{a}$ \\
\hline Notches out of tail fold & 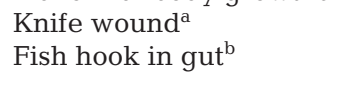 & $\begin{array}{l}\text { Old, calcified scar } \\
\text { Breaks in fin } \\
\text { rays/cartilage }^{\mathrm{a}}\end{array}$ \\
\hline
\end{tabular}



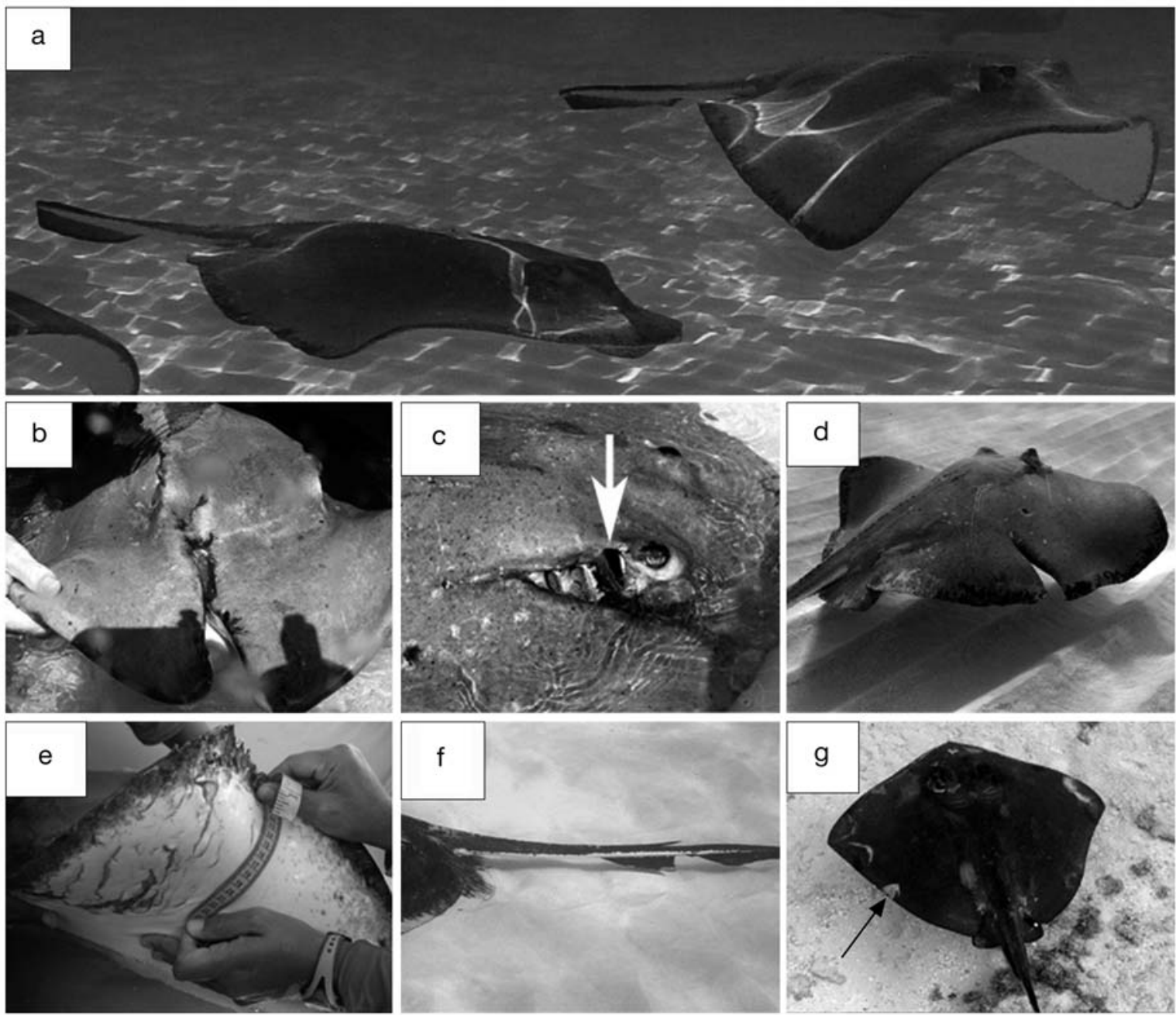

Fig. 2. Dasyatis americana. Types of injuries recorded at the tourist site: (a) predator-detection injury (missing tail); (b) susceptible-to-infection wound (propeller caused, now sustained by swimming into anchor ropes); (c) susceptible-to-infection wound (propeller caused, note exposed gills; arrow indicates spiracle opening); (d) motility-impairment injury (propeller caused); (e) predator bite mark, fresh; (f) predator bite mark (notch out of tail fold); and (g) conspecific bite marks (arrow indicates fresh bite wound). Photographs (a) to (d), (f) and (g) courtesy of Mathew Potenski; photograph (e) courtesy of Ben Bondzio

and damaged tails could not necessarily be attributed to predation attempts since propellers can also be the cause of these injuries. However, with regards to obvious predator bite wounds and scars (i.e. teeth marks and/or notches out of the tail-fold; Fig. 2e,f), stingrays from tourist sites had more than twice the number of predator wounds (13 rays out of 46 ) than those from non-tourist sites (6 of 50 rays).

\section{Parasite loads}

The likelihood of a stingray being host to a dermal/gill isopod parasite was significantly affected by stingray size, body condition and location $\left(\chi^{2}\right.$ model $=$ $36.60, \mathrm{p}<0.001)$. Larger stingrays, stingrays with larger body size residuals and stingrays at the tourist site were more likely to have parasites located in their spiracles $\left(\chi_{\text {disc width }}^{2}=27.33, \mathrm{p}=0.001, \beta=-10.85 ; \chi_{\text {body }}^{2}\right.$ condition $=6.94, \mathrm{p}=0.008, \beta=-0.43 ; \chi^{2}$ location $=4.47, \mathrm{p}=$ $0.035, \beta=1.63$, respectively). When exploring the effect of body condition in more detail, it was found that this variable was significant for stingrays from non-tourist sites only $\left(\chi_{\text {model }}^{2}=3.95, \mathrm{p}=0.04, \beta_{\text {non-tourist }}\right.$ $=-0.19$ ). All but 1 stingray from the tourist site had spiracle parasites (a $37 \mathrm{~cm}$ disc width female; $\mathrm{n}=45$ ), and 8 of the 50 rays sampled from the non-tourist sites were free of spiracle parasites (Fig. 1).

Excluding rays with no spiracle parasites, the average number of parasites per ray (square-root transformed) was significantly higher at the tourist site, with the significant effect of disc width included in the 
model $\left(\mathrm{R}^{2}{ }_{\text {adj }}=0.37, t_{\text {disc width }}=5.31, \mathrm{p}=0.001, t_{\text {location }}=\right.$ $-2.20, \mathrm{p}=0.031$, effect size $=0.5$; least squares backtransformed means \pm SE: $9.1 \pm 1.7$ and $6.7 \pm 1.7$ parasites per stingray from tourist and non-tourist sites, respectively; Table 1). There was no effect of body condition.

\section{Conspecific bite marks}

With both sexes included in the model, large stingrays and stingrays from the tourist site had a higher likelihood of being bitten by conspecifics $\left(\chi_{\text {model }}^{2}=145.83, \mathrm{p}<0.001 ; \chi^{2}{ }_{\text {disc width }}=39.16, \mathrm{p}=0.001\right.$, $\beta=-6.18 ; \chi^{2}$ location $\left.=22.77, \mathrm{p}<0.001, \beta=6.62\right)$. Although sex was not a significant predictor, this was most likely due to the fact that the majority of small rays were also males. With respect to the number of bite marks per individual, all of the rays sampled at the tourist site had at least 1 CBM $(n=90)$. At the non-tourist sites, only $48 \%$ of the rays exhibited CBMs $\left(n_{\text {total }}=79\right.$; and $68 \%$ of females, $n_{\text {females }}=53$ ). Count data of CBMs were analysed separately for each sex. No statistical analysis was performed on males from the non-tourist site due to the low incidence of bite marks in general. Of the 19 immature males sampled at the non-tourist sites (34 to $44 \mathrm{~cm}$ disc width), 1 had a single CBM (39 $\mathrm{cm}$ disc width). Four mature males were caught (48 to $54 \mathrm{~cm}$ disc width), and 1 individual only (48 $\mathrm{cm}$ disc width) had a single CBM (Table 1). Of the males at the tourist site $(\mathrm{n}=14), 3$ were immature and ranged from 39 to $47 \mathrm{~cm}$ disc width. Mature males ranged from 49 to $68 \mathrm{~cm}$ disc width. All males had bite marks. There was no significant effect of disc width or maturity stage on the number of CBMs per individual male (Poisson GLM: $\chi^{2}{ }_{\text {model }}=10.4, \mathrm{p}=0.005 ; \beta_{\text {disc width }}=1.09, \chi^{2}=2.35$, $\left.\mathrm{p}=0.12 ; \beta_{\text {immature } / \text { mature }}=-0.16, \chi^{2}=0.10, \mathrm{p}=0.75\right)$. The median number of bite marks for immature males was 7; that for mature males was 14 (Table 1).

Females stingrays were divided into size categories: $\leq 65,66$ to 90 and $\geq 91 \mathrm{~cm}$ disc width, and CBM count data were compared between tourist and non-tourist sites (with females with no CBMs excluded from analysis). In addition to the significant location and sizecategory effects (Poisson GLM: $\chi_{\text {model }}^{2}=111.6, \mathrm{p}=$ $0.005 ; \chi_{\text {location }}^{2}=23.38, \mathrm{p}<0.001 ; \chi_{\text {size category }}^{2}=28.39$, $\mathrm{p}<0.001)$, there was also a significant interaction effect between these 2 variables $\left(\chi^{2}\right.$ location $\times$ size category $=$ 13.67, $\mathrm{p}=0.001$ ). The size-category effect was consequently explored separately for each location using contrast analysis. Specifically, amongst non-tourist females, the number of CBMs in the 66 to $90 \mathrm{~cm}$ disc width category $(n=24)$ was significantly higher than in the $\leq 65 \mathrm{~cm}$ disc width category $\left(\mathrm{n}=6 ; \beta=1.21, \chi^{2}=\right.$ 5.13, $p=0.02$; median CBMs: 5 vs. 0; Table 1). Females $\geq 91 \mathrm{~cm}$ disc width $(\mathrm{n}=8)$ had significantly more CBMs than females in the mid-size category $\left(\beta=1.08, \chi^{2}=\right.$ 27.86, $\mathrm{p}<0.001$; median CBMs: 15 vs. 5). This pattern was dissimilar amongst the tourist rays in that, while mid-size category females $(\mathrm{n}=15)$ had more CBMs than the smallest size category $\left(\mathrm{n}=6 ; \beta=1.01, \chi^{2}=\right.$ 10.27, $\mathrm{p}=0.001$; median CBMs: 22 vs. 6 ), the largest sized females $(\mathrm{n}=54)$ did not have significantly more CBMs than females ranging between 66 and $90 \mathrm{~cm}$ disc width $\left(\beta=-0.02, \chi^{2}=0.04, p=0.84\right)$. They had, in fact, slightly fewer median bite marks (21 vs. 22, respectively; Table 1).

\section{DISCUSSION}

The present study set out to explore whether the change in stingray Dasyatis americana behaviour, namely the permanently aggregative attraction to tourist-induced stimuli (i.e. provisioning of food), imposed detectable costs. We found that in comparison to stingrays from non-tourist sites around Grand Cayman, those from tourist sites are more likely to be in lower body condition, injured, susceptible to ectodermal parasites, and engaged in intense interference competition. Stingrays from tourist sites also have significantly higher mean numbers of injuries and parasites and median CBMs. Studying fitness repercussions of altered behaviours attributable to the effects of marine provisioning-tourism is complicated owing to the inaccessibility of the marine environment, the longevity of the species in which effects may be manifested only long-term (e.g. dolphin provisioning at Moreton Island, Australia; Neil \& Brieze 1998), the indirect interaction effects on non-target species (e.g. increased predation frequency on damselfish nests by target-fed labrid species; Milazzo et al. 2006), and the seasonality of the tourism attraction, in which changes in behaviours are consequently temporary (e.g. white shark provisioning in South Africa; Laroche et al. 2007). With the provisioning of stingrays at SCS, the effects of novel grouping behaviours can be readily investigated because the shallow-water habitat is readily accessible; the attraction has been in operation for approximately $20 \mathrm{yr}$; and these long-lived stingrays exhibit strong site fidelity owing to the year-round activities at the site.

\section{Injury frequency, type}

The positive response of stingrays to the presence of tourists engenders a large injury cost. The majority of rays at the tourist site were injured, and those injured had almost twice as many injuries as those from non- 
tourist sites, even after controlling for size. These results are not due to the animals being older at SCS and hence accumulating wounds with age. The proportion of injured rays is not significantly different between the 3 size categories at SCS; however, the proportion injured at the non-tourist sites does increase with size. These results suggest that SCS represents a riskier environment for the rays in terms of injury hazards compared with wild habitats.

Boat collisions are generally the dominant form of injuries to animals that are the focus of marine-based tourism attractions (e.g. manatees, dolphins, whales; Aipanjiguly et al. 2003, Bejder \& Samuels 2003, Lusseau 2005). The majority of injuries incurred at SCS, regardless of injury type, are indeed caused by boat propellers, anchor chains, or anchors that have resulted in a myriad of boat-related injuries (Table 2, Fig. $2 b-d)$. As for obvious predator scars or injuries at SCS (Fig. 2e,f), if we assume that predator-injury frequencies reflect capture rates rather than rates of survival following capture, the tourist site also represents a higher predation risk to stingrays than do the non-tourist environments sampled (as stingrays from tourist sites had more than twice the number of predator wounds). This is discussed in more detail below.

\section{Parasite loads}

Another cost of grouping is increased parasite transmission due to the facilitation of transfer between animals that are in closer contact, such as in groups, compared to single individuals. The type of parasites in stingrays' spiracles are mobile flabelliferan isopods of the family Aegidae. These parasites seek their hosts actively by swimming in the water column until they can settle on the animal to feed. Aegid isopods feed on whole blood, and can be found in sharks and rays on the skin, buccal and branchial chambers, and gills.

At SCS, all but 1 ray was host to a spiracle parasite, and had, on average, one-third more parasites than rays from non-tourist sites after controlling for body size. Isopods are considered to be an emerging problematic taxon, especially in aquarium-confined elasmobranchs, due to their health impacts on the host. For instance, isopods are known to cause gill and skin lesions and blood loss. Heavy infections may cause osmotic imbalance, deleterious metabolic demands, and may open lesions facilitating invasion by opportunistic pathogens (Benz \& Bullard 2004). Parasite counts at the tourist site were as high as 32 parasites per ray, and were confined to the spiracles. It is therefore possible that because of the high density of rays and the strong temporal and spatial fidelity to the tourist site, stingrays may have altered distribution and density loads of aegid or other parasite families located directly on their gills or in other body locations (e.g. trematodes) that were inaccessible to our non-invasive sampling methods. It would be worthwhile, therefore, to determine if any physiological changes have occurred in the ability to respond to the intense prevalence of ecto-parasites in stingrays at SCS.

\section{Conspecific bite marks}

When animals incidentally group in the course of acquiring resources such as food or mates, interference competition over the resource can result, especially if it is concentrated either temporally or spatially (Case \& Gilpin 1974). Every ray sampled at the tourist site showed evidence of CBMs. The most likely explanation for this high incidence can be attributed to aggressive interference competition over the centrally provisioned food sources. Exploitative competition cannot explain the occurrence of CBMs, as this would occur if the resource was limited (which it is not). However, 2 alternative hypotheses can be used to explain the high incidence of bites: increased mating effort and indiscriminate biting over the food resource. With regards to the first hypothesis, male stingrays bite the edges of the female's fins to secure a hold when attempting internal fertilization, thereby producing scrapes, abrasions, or wounds in the process (Kajiura et al. 2000). Large males can also exhibit bite marks from mistaken identity or competition over females. Females become reproductively mature at approximately $75 \mathrm{~cm}$ disc width (Henningsen 2000), a larger size than males at maturity $(47 \mathrm{~cm})$. We would not expect immature males or small females to possess any bite marks (akin to the stingrays from the non-tourist sites), even through accidental or competitive mating attempts, since they are too small to be reproductively fertile. Nevertheless, our results indicate that these smaller rays still show a high frequency of bite marks. Moreover, we would not expect the largest females to have the same number of bite marks than mid-sized females (unlike the stingrays from nontourist sites, in which the largest rays have 3 times as many CBMs). Since fecundity increases with size (Henningsen 2000), larger females should be preferred. Also, as mature females are not a limiting resource to mature males (they outnumber males 7:1; from unpublished tagging data from 2002 to 2005), smaller females should not be experiencing the same intensity of male courtship. Again, our results do not support these expected outcomes.

The second hypothesis concerns stingrays mistakenly biting conspecifics in the scramble competition over the food resource. The mouth of a stingray is ventrally positioned, and, since a ray locates its food 
through electroreception, it can indiscriminately bite any ray passing underneath. This occurrence may also explain the multitude of bite marks on the rays. However, we would therefore expect to see the largest animals having the highest number of bites, as, due to their sheer size and number (they outnumber midsized females 2.5:1), they would be most likely to 'get in the way'; we did not find this. An alternative explanation is that of increased aggression and dominance. Because the food provisioning is done from a concentrated source, namely from around one of the many floating buckets in the water, an individual positioning itself as close to the source as possible would ensure a high probability of food capture. Large females have been observed to display pushy behaviour, ramming themselves into tourists holding food, and actively biting and pursuing other stingrays nearby. This sizedependent, dominant-aggressive behaviour of large females has also been noted at the other stingray-feeding tourist attraction in Western Australia (Newsome et al. 2004): females at Hamelin Bay were observed shoving other rays (as well as tourists) with their snouts, and aggressively chasing smaller males away from the feeding site. Being more dominant than smaller females and males, larger females at SCS should therefore be most active in biting subordinates in the water, and therefore not necessarily exhibit the most number of bite marks themselves.

As the majority of fresh wounds recorded on rays from the 2005 season stemmed from CBMs, the aggression and competition between stingrays at the tourist site may have health implications. Open wounds can be sources of pathogen entry, or tax the ray's allostatic abilities (the cumulative result of physiological allocation in relation to environmental stimuli) with resultant effects on long-term health (McNamara \& Buchanan 2005). In addition, high levels of activity associated with aggressive interference competition for food can lead to greater energy expenditure, elevated metabolic rates, decreased food utilization efficiency and impaired immune function, as have been shown in aquaculture fish (reviewed in Ashley 2007). These potential physiological outcomes require further investigation.

\section{Benefits of grouping}

As mentioned previously, the decision of animals to join or remain in a group depends on a balance of the associated costs and benefits. The resource dispersion hypothesis (RDH) (Macdonald 1983) proposes a mechanism for the passive formation of social groups where resources are dispersed, even in the absence of any benefits of group-living per se (Johnson et al. 2001). An alternative explanation to group-living is that, should costs be substantial, animals may still choose to live in groups since the benefits accrued are still relatively greater. Lastly, and particularly relevant to anthropogenically altered habitats, animals may aggregate due to perceived and immediate benefits, but may unknowingly incur relatively greater costs in the, longer term. This last phenomenon is known as an ecological trap (Schlaepfer et al. 2002). According to the $\mathrm{RDH}$, rays at SCS may be forming groups because, whilst there may be no intrinsic benefits, the costs of doing so are trivial. We believe, however, that the general costs in this tourist system are not insignificant, in particular, the risk level of the habitat with regard to injury hazards. However, associating a risk with an area can lead to its avoidance (Whittaker \& Knight 1998). Despite this risk, SCS stingrays are continuing to form dense aggregations. As such, these rays may be accruing possible advantages. The 2 most beneficial outcomes of group-living are typically increased vigilance and numeric dilution. Both factors can reduce the chances that individual group members will suffer fitness losses due to predation (Krause \& Ruxton 2002).

With regards to vigilance, stingrays primarily rely on vision to detect approaching predators, namely sharks (Semeniuk \& Dill 2005). While feeding at SCS, stingrays are engaged in intense interference competition, an unnatural behaviour, and may consequently be less vigilant of predators and more vigilant of conspecifics (Cresswell 1997). Stingrays can also detect predators via the mechanoreceptors along the length of their body and tail (which senses differential changes in water pressure; Maruska \& Tricas 1998). At SCS, however, $65 \%$ of rays sampled at the tourist site had predator-detection/defence injuries (i.e. shortened, damaged tails, Fig. 2a), suggesting that their secondary means of vigilance is also impaired. As tails can be considered expendable body parts to predators, shortened tails can furthermore increase a ray's vulnerability (Semeniuk \& Dill 2006); $10 \%$ of the injured tails were shortened above the positioning of the barb, which additionally impedes defence. Furthermore, $40 \%$ of sampled rays had motility-impairment injuries, which could affect the speed at which a ray can flee from a predator. Finally, increased group size has been demonstrated to hinder the escape ability and speed of an individual ray (Semeniuk \& Dill 2005). We also believe that stingrays may not be benefiting from the dilution effect. Large groups can be more conspicuous and may therefore attract more predators (Krause \& Godwin 1995). Because the stingray relies on crypsis (by burying itself in the sand) as its main predatoravoidance strategy from visually searching predators during the day, the forming of large milling groups 
around the food source may attract predators at a higher frequency rate, thus reducing the net benefits incurred through dilution. The higher incidence of predator bite marks would therefore lend credence to this supposition. Tourists themselves do not act as deterrents to predators, as sharks are visibly apparent at SCS, and efforts to cull them from the immediate vicinity take place whenever they are detected (Tim Austin, Assistant Director, Cayman Islands Department of Environment, pers. comm.).

Another possible benefit to rays at the tourist site, indirectly related to group-living, could be the increased time allocated to activities other than foraging efficiency. Because tourist food can be obtained at little or no energy cost, alternative allocated activities can be either rest, growth, or reproduction. Extra resting time may be beneficial for stingrays from tourist sites so that they can invest energy into allostatic maintenance, and resistance to and repair of parasitic impacts and injuries. However, a recent acoustic-telemetry tracking study of Cayman Island stingrays demonstrated that, although they had a much smaller activity space, stingrays from tourist sites did not have significantly lower rates of movement $\left(\mathrm{km} \mathrm{h}^{-1}\right)$ than those from non-tourist sites (Corcoran 2006). These findings suggest that, despite having a readily available, centralized food source, stingrays are still as active as they would be under natural conditions and are therefore not accruing the advantages of additional resting time. Alternatively, stingrays can be capitalizing on the surplus resource and allocating it to faster growth rates and/or reproduction. This may certainly explain why stingrays are larger at the tourist site, but would not explain why the rays would then have lower body condition. In addition, since larger females have larger litter sizes (Henningsen 2000), females may also be trading off the costs of grouping with higher fecundity (although we would have then expected residuals of the length-weight relationship for tourist rays to be positive, not negative, if this were the case; Table 1). We believe the poorer body condition of stingrays from tourist sites is indicative of the cumulative, long-term effects of provisioning tourism. At this time, the potential positive impacts of provisioning tourism cannot be supported without further examination.

\section{CONCLUSION}

Many studies that have investigated the impacts of humans on the behaviour of wildlife have established that species respond to people as if they were predators. In the present study, we show that, while some tourism activities can instead be considered a positive stimulus and thus attract animals, costs still do occur. Suggested costs of grouping, used to explain present-day occurrence of solitary living in animal systems, are equally applicable to and empirically evidenced in this study of a population that has traditionally been solitary and has transitioned only recently to group-living. Because these costs are being experienced continuously, fitness consequences can result. Animals under chronic stress should allocate resources so as to minimize the risk from the current threats, while not compromising long-term survival by incurring too much damage (i.e. reduced physiological reserves of essential nutrients, increased levels of oxidative stress, or reduced body condition) to individual physiological state (McNamara \& Buchanan 2005). If stingrays at the tourist site are not allocating the surplus of food resources to increased rest (and hence addressing the costs of increased injuries, parasites and aggression) and because of the unnatural balance of essential fatty acid ratios from their diet (Semeniuk et al. 2007) that is important for disease resistance, stress-management and gamete quality, it is possible that the tourist rays may be experiencing negative physiological and immunological impacts that can affect long-term fitness. Consequently, we are currently examining these physiological impacts (authors' unpubl. data). Indeed, should there be no investment of energy into somatic and/or reproductive growth, or, equally, should the following generations of stingrays born from SCS rays seek out the tourist site themselves, then the distinct possibility exists that SCS will represent an ecological trap for southern stingrays, more so than simply a risky habitat. From a management perspective, long-term monitoring and management of the tourist site is therefore required.

Education and awareness of the risks posed to stingrays are other key tactics in mitigating the negative impacts of tourism. Furthermore, measures should be taken to alleviate crowding conditions at SCS by limiting the number of people and boats, or by expanding the site into nearby areas to accommodate the current level. Less food provisioned to the rays would also alleviate interference competition, and ensure that the rays resume foraging naturally and solitarily, further away from the tourist site. Additionally, safety devices on boat propellers, such as cages and guards, can also aid in reducing injuries.

Acknowledgements. C.A.D.S and K.D.R. acknowledge financial support from Fonds Québécois de la Recherche sur la Nature et les Technologies (FQRNT) and the National Sciences and Engineering Research Council of Canada (NSERC), respectively. This work was partially supported by a PADI AWARE research grant. Stingrays were caught and examined under a Cayman Islands research permit and Simon Fraser University animal care protocol No. 708R-04. We thank the following individuals for their assistance in the field: J. Verspoor, R. Wrangham, K. Donnawell, B. Bondzio, M. Potenski, J. Bothwell, M. Orr, B. Johnson, J. Blumenthal, 
D. Blumenthal, A. Briggs, and C. Sherrit. We also thank the Cayman Island Department of Environment and the Guy Harvey Research Institute for the use of marine and laboratory equipment.

\section{LITERATURE CITED}

Aipanjiguly S, Jacobson SK, Flamm R (2003) Conserving manatees: knowledge, attitudes, and intentions of boaters in Tampa Bay, Florida. Conserv Biol 17:1098-1105

Amo L, López P, Martin J (2006) Nature-based tourism as a form of predation risk affects body condition and health state of Podarcis muralis lizards. Biol Conserv 131: 402-409

Ashley P (2007) Fish welfare: current issues in aquaculture. Appl Anim Behav Sci 104:199-1123

> Beale CM, Monaghan P (2004) Human disturbance: people as predation-free predators? J Appl Ecol 41:335-343

Bejder L, Samuels A (2003) Evaluating the effects of naturebased tourism on cetaceans. In: Gales N, Hindell M, Kirkwood R (eds) Marine mammals: fisheries, tourism and management issues. CSIRO Publishing, Collingwood, p 229-256

Benz GW, Bullard SA (2004) Metazoan parasites and associates of chondrichthyans with emphasis on taxa harmful to captive hosts. In: Smith M, Warmolts D, Thoney D, Hueter R (eds) The elasmobranch husbandry manual: captive care of sharks, rays and their relatives. Special Publication, Ohio Biological Survey, Columbus, $\mathrm{OH}$, p 325-416

Blumstein DT (2006) Developing an evolutionary ecology of fear: how life history and natural history traits affect disturbance tolerance in birds. Anim Behav 71:389-399

Case TJ, Gilpin ME (1974) Interference competition and niche theory. Proc Natl Acad Sci USA 71:3073-3077

Chapman DD, Corcoran MJ, Harvey GM, Malan S, Shivji MS (2003) Mating behavior of southern stingrays, Dasyatis americana (Dasyatidae). Environ Biol Fishes 68: 241-245

Corcoran M (2006) The effects of supplemental feeding on the activity space and movement patterns of the southern stingray, Dasyatis americana, at Grand Cayman, Cayman Islands. MSc thesis, Nova Southeastern University, Fort Lauderdale, FL

Cresswell W (1997) Interference competition at low competitor densities in blackbirds Turdus merula. J Anim Ecol 66:461-471

Dahlberg MD (1970) Frequencies of abnormalities in Georgia estuarine fishes. Trans Am Fish Soc 99:95-97

Duffus DA, Dearden P (1990) Non-consumptive wildlifeorientated recreation: a conceptual framework. Biol Conserv 53:213-231

Frid A, Dill LM (2002) Human-caused disturbance stimuli as a form of predation risk. Conserv Ecol 6(1):11, available at: www.consecol.org/Journal/vol6/iss1/art11/manuscript. html

Gill JA, Sutherland WJ (eds) (2000) Predicting the consequences of human disturbance from behavioural decisions. Cambridge University Press, Cambridge

Gilliam D, Sullivan KM (1993) Diet and feeding habits of the southern stingray Dasyatis americana in the Central Bahamas. Bull Mar Sci 52:1007-1013

Henningsen AD (2000) Notes on reproduction in the southern stingray, Dasyatis americana (Chondrichthyes: Dasyatidae), in a captive environment. Copeia 2000:826-828

Henningsen AD (2002) Age and growth in captive southern stingrays, Dasyatis americana. Abstract presented at the 2002 Annual Meeting of American Elasmobranch Society, Kansas City, KS

> Ikuta LA, Blumstein DT (2003) Do fences protect birds from human disturbance? Biol Conserv 112:447-452

Johnson DDP, Baker S, Morecroft MD, Macdonald DW (2001) Long-term resource variation and group size: a largesample field test of the resource dispersion hypothesis. BioMed Central Ecol 2:1

Kajiura SM, Sebastian AP, Tricas TC (2000) Dermal bite wounds as indicators of reproductive seasonality and behavior in the Atlantic stingray, Dasyatis sabina. Environ Biol Fishes 58:23-31

Knight RL, Cole DN (1995) Wildlife responses to recreationists. In: Knight RL, Gutzwilller KJ (eds) Wildlife and recreationists: coexistence through management and research. Island Press, Washington, DC, p 51-69

Krause J, Godin JGJ (1995) Predator preferences for attacking particular group sizes: consequences for predator hunting success and prey predation risk. Anim Behav 50:465-473

Krause J, Ruxton GD (2002) Living in groups. Oxford University Press, Oxford

Laroche RK, Kock AA, Dill LM, Oosthuizen WH (2007) Effects of provisioning ecotourism activity on the behaviour of white sharks Carcharodon carcharias. Mar Ecol Prog Ser 338:199-209

Lima SL, Dill LM (1990) Behavioral decisions made under the risk of predation: a review and prospectus. Can J Zool 68:619-640

Lusseau D (2003) Male and female bottlenose dolphins Tursiops spp. have different strategies to avoid interactions with tour boats in Doubtful Sound. Mar Ecol Prog Ser 257:267-274

Lusseau D (2005) The residency pattern of bottlenose dolphins (Tursiops spp.) in Milford Sound, New Zealand, is related to boat traffic. Mar Ecol Prog Ser 295:265-272

Macdonald DW (1983) The ecology of carnivore social behaviour. Nature 301:379-384

Maruska KP, Tricas TC (1998) Morphology of the mechanosensory lateral line system in the Atlantic stingray, Dasyatis sabina: the mechanotactile hypothesis. J Morphol 238:1-22

McNamara JM, Buchanan KL (2005) Stress, resource allocation, and mortality. Behav Ecol 16:1008-1017

Milazzo M, Anastasi I, Willis TJ (2006) Recreational fish feeding affects coastal fish behavior and increases frequency of predation on damselfish Chromis chromis nests. Mar Ecol Prog Ser 310:165-172

Müllner A, Linsenmair KE, Wikelski M (2004) Exposure to ecotourism reduces survival and affects stress response in Hoatzin chicks (Opisthocomus hoazin). Biol Conserv 118: 549-558

Neil DT, Brieze I (1998) Wild dolphin provisioning at Tangalooma, Moreton Island: an evaluation. In: Tibbetts IR, Hall NJ, Dennison WC (eds) Moreton Bay and catchment. School of Marine Science, The University of Queensland, Brisbane, p 487-500

Nevin OT, Gilbert BK (2005) Measuring the cost of risk avoidance in brown bears: further evidence of positive impacts of ecotourism. Biol Conserv 123:453-460

Newsome D, Lewis A, Moncrieff D (2004) Impacts and risks associated with developing, but unsupervised, stingray tourism at Hamelin Bay, Western Australia. Int J Tourism Res 6:305-323

Newsome D, Dowling R, Moore S (2005) Wildlife tourism. Channel View Publications, Clevedon 
Orams MB (2002) Feeding wildlife as a tourism attraction: a review of issues and impacts. Tourism Manage 23: 281-293

Reynolds PC, Braithwaite D (2001) Towards a conceptual framework for wildlife tourism. Tourism Manage 22:31-42

Rubenstein D (1998) Behavioral ecology and conservation policy: on balancing science, applications, and advocacy. In: Caro $\mathrm{T}$ (ed) Behavioral ecology and conservation biology. Oxford University Press, Oxford p 527-553

Schlaepfer MA, Runge MC, Sherman PW (2002) Ecological and evolutionary traps. Trends Ecol Evol 17:474-480

Semeniuk CAD, Dill LM (2005) Cost/benefit analysis of group and solitary resting in the cowtail stingray, Pastinachus sephen. Behav Ecol 12:417-426

Semeniuk CAD, Dill LM (2006) Anti-predator benefits of mixed-species groups of cowtail stingrays (Pastinachus sephen) and whiprays (Himantura uarnak) at rest. Ethol-

Editorial responsibility: Matthias Seaman,

Oldendorf/Luhe, Germany ogy 112:33-43

Semeniuk CAD, Speers-Roesch B, Rothley KD (2007) Using fatty acid profile analysis as an ecological indicator in the management of tourist impacts on marine wildlife: a case of stingray-feeding in the Caribbean. Environ Manag 40:665-677

Shackley M (1998) 'Stingray City' — managing the impact of underwater tourism in the Cayman Islands. J Sustain Tourism 6:328-338

Steenbeek R, van Schaik CP (2001) Competition and group size in Thomas's langurs (Presbytis thomasi): the folivore paradox revisited. Behav Ecol Sociobiol 49:100-110

Tricas TC, Deacon K, Last P, McCosker JE, Walker TI, Taylor L (1997) Nature Company guides: sharks and rays. Time Life Book Series, Weldon Owen Pty, San Francisco, CA

Whittaker D, Knight RL (1998) Understanding wildlife response to humans. Wildl Soc Bull 26:312-317

Submitted: August 13, 2007; Accepted: October 23, 2007

Proofs received from author(s): March 24, 2008 